\section{Grass and Olea Airborne Pollen Allergens in Outdoor Air Samples and its Correlation with Pollen Counts}

S. Ladeira ${ }^{1}$, C. Nunes ${ }^{1}$, R. Ferro ${ }^{2}$, R. Ferro ${ }^{2}$, M. Martins ${ }^{2}$, E. Caeiro ${ }^{2}$, C. Antunes $^{2}$, R. Brandao ${ }^{2}$, A. Caldeira ${ }^{2} ;{ }^{1}$ Center of Allergy of Algarve, Portimao, PORTUGAL, ${ }^{2}$ University, Evora, PORTUGAL.

RATIONALE: In Portugal, grass and Olea europaea pollen are certainly one of the main sources of athmospheric aeroallergens and as such, one of the main causes of respiratory allergy.

For these reasons, it is useful the development of new strategies for prevention and treatment of these pathologies. The aim of this study was to evaluate the putative correlation between the concentration of some of the major allergens of and with their pollen counts.

METHODS: On a meteorological platform at the town center of Evora (south Portugal), ambient air was sampled at $800 \mathrm{~L} / \mathrm{min}$ with a Chemvol high-volume cascade impactor equipped with stages $\mathrm{PM}>10 \mu \mathrm{m}, 10$ $\mu \mathrm{m}>\mathrm{PM}>2.5 \mu \mathrm{m}$. The polyurethane impacting substrate was extracted with $0.1 \mathrm{M}$ NH4HCO3, pH8.1, supplemented with $0.1 \%$ BSA. The major pollen allergens from grass Phleum $\mathrm{p} 5$ and olive Ole e 1 were determined with allergen specific ELISA's. Airborne pollen of and Olea europaea simultaneously monitored with a Burkard Seven Day Recording Volumetric Spore TrapÒ, between the 30th of April and the 8th of July of 2009. Both samplers were placed side-by-side with air input at the same level.

RESULTS: During the pollen season of 2009, high values of grass pollen were recorded between May 2th and June 1 th. It was also observed that the air content of $\mathrm{Phl} \mathrm{p5}$ or Ole e1 aeroallergens were directly correlated with airborne pollen counts of Poaceae and Oleaceae, respectively.

CONCLUSIONS: Results suggest that the directly quantification of aeroallergens may contribute, together with pollen counts of air samples, to define the allergic risk with higher precision.

\section{6} Pollen Viability under a Stress Condition R. Codina, R. E. Esch, T. C. Coyne; Greer Laboratories, Lenoir, NC.

RATIONALE: Experiments have suggested that pollen viability could be an indicator of air pollution. This testing could potentially replace the pesticides and heavy metals measurement currently performed to evaluate that parameter. The purpose of this exploratory study was to ascertain the efficacy of a stain to evaluate the viability of different pollen species under an artificial stress condition.

METHODS: Timothy grass, short ragweed, and white oak pollen species were stored at $35 \mathrm{oC}$ for one month. Pollen viability was measured at time 0 and after 1, 5, 10, 20, and 30 days of storage using p-phenylenediamine to detect the presence of myeloperoxidase. A minimum of 150 pollen grains were examined by optical microscopy. Pollen grains were considered viable if they turned totally black. All samples were extracted at the end of the study. Bradford protein content was measured and qualitative protein profile was analyzed by SDS-PAGE.

RESULTS: The discrimination between viable and non-viable pollen was efficient for oak and controversial for ragweed. The percents of viable Timothy grass, oak, and short ragweed pollen at time 0 were $93.1 \%$, $58.8 \%$, and $100 \%$, respectively. The respective percents at the end of the study were $0.0 \%, 16.2 \%$, and $18.3 \%$. No substantial changes in total protein content and protein profile were observed at any testing time compared with the respective baseline levels.

CONCLUSION: Myeloperoxidase staining could be a sensitive marker of pollen integrity for some species. This test could have potential applications in different areas. Additional experiments in the laboratory should be performed before initiating field experiments. 657 Grasses Pollen Concentrations In The Atmosphere Of

E. Caeiro ${ }^{1}$, C. Nunes ${ }^{2}$, R. Brandao ${ }^{3}$, L. Lopes ${ }^{3}$, A. Gaspar ${ }^{4}$, M. Almeida ${ }^{4}$; ${ }^{1}$ University of Evora, Portimao, PORTUGAL, ${ }^{2}$ Center of Allergy of Algarve, Portimao, PORTUGAL, ${ }^{3}$ University of Evora, Evora, PORTUGAL, ${ }^{4}$ CUF Descobertas, Lisboa, PORTUGAL.

RATIONALE: To compare the main pollination season (MPS) of Poaceae pollen from different monitoring stations of the Portuguese Aerobiology Network (RPA): Oporto (north), Coimbra and Lisbon (center), Évora and Portimão (south); 2) to analyse the interannual and diurnal variations of Poaceae pollen concentrations in the atmosphere of each station.

METHODS: Airborne pollen was collected with Hirst-type samplers, most of them on rooftops or meteorological platforms, 15-20 m above ground floor. In this study, daily and hourly sampling data of Poaceae pollen from five monitoring stations over the last seven years (2002-2008) were used.

RESULTS: There are differences between years. Daily average concentrations above 25 pollen grains $/ \mathrm{m} 3$ were recorded in Oporto during $23 \pm 5$ days, $16 \pm 8$ days in Coimbra, in Lisbon during $34 \pm 15$ days, in Évora $54 \pm 9$ days and in Portimão $39 \pm 12$ days. Poaceae pollen was recorded in the atmosphere during 24 hours, with the lowest values recorded between $22 \mathrm{~h}$ and $6 \mathrm{~h}$ and the highest values observed in Évora between $7 \mathrm{~h}$ and $21 \mathrm{~h}$, where more than 30 pollen grains $/ \mathrm{m} 3$ were recorded.

CONCLUSIONS: Between the stations there were differences, in terms of quantity and other features by the different environmental conditions. The risk of exposure to this pollen is higher in the southern inland areas and rural areas.

58 Evolution of Relative Abundance of Various Tree, Grass and 658 Weed Pollens in Vinnitsa, Ukraine, from 1999 to 2010 as an Index of Climate Change

V. Rodinkova ${ }^{1}$, O. Bilous ${ }^{1}$, L. Kremenska ${ }^{1}$, O. Palamarchuk ${ }^{1}$, L. M. DuBuske ${ }^{2}$; Vinnitsa National Medical University, Vinnitsa, UKRAINE, ${ }^{2}$ Immunology Research Institute of New England, Gardner, MA.

RATIONALE: Changes in tree and weed pollination in Vinnitsa, a city in the forest-steppe zone of Ukraine were assessed from 1999-2000 to 20092010 to provide insight into climate change and predict future trends in allergic respiratory diseases.

METHODS: Pollen counts from 1999-2000 years were obtained at Vinnitsa National Pirogov Memorial Medical University (VNMU) by gravimetric sampling while in 2009- 2010 employed volumetric Hurst Burkard trap.

RESULTS: Betula, Carpinus and Amaranthus/Chenopodiaceae pollen group were the most abundant pollens in 1999-2000 while stinging nettle (Urtica dioica) led in 2009-2010 with a share of $44 \%$ for 2009 and $30 \%$ for 2010 while being in $16^{\text {th }}$ and $12^{\text {th }}$ position of abundance in 1999 and 2000 respectively. Pinus was the second most abundant pollen in 2009 and Betula pollen was second in 2010. Carpinus pollen was $15^{\text {th }}$ most abundant in 2009 and $7^{\text {th }}$ in 2010. Ambrosia was 8th in abundance in 1999 and 10th in 2000 and remained 8thin 2009.

CONCLUSIONS: Quantity of Urtica pollen has become greater than in the last 10 years in Vinnitsa. Whereas Betula pollen remains highly abundant pollen other species including Carpinus and Amaranthus/ Chenopodiaceae pollen are relatively less abundant, being replaced by Pinus, Betula, Alnus and Poaceae pollen and Ambrosia pollen abundance, which is growing elsewhere in Eastern and Central Europe, has remained static. These changes in abundance of various pollens may reflect global climate change and may influence future patterns of respiratory allergic disease manifestation. 